\title{
RECENT THEORIES OF THE SULPHURIC ACID PROCESS.*
}

Br Williay R. Potser.

In preparing the notes which follow, my chief regret has been that I have little or nothing of an original character to communicate to the society upon this occasion. Having devoted the greater portion of my timeand energy during the past six years to a fow processes of technical chemistry, original work, other. than that connected with that branch, has been almost impossible; and the subject which I have the pleasure to bring to your notice this evening is probably, in a general way at least, familiar to all present. For from the time when the student receives his first introduction to test tubes and reagents until his chemical career is ended, sulphuric acid is his almost inseparable companion. As usually explained in the text books on chemistry, one would very readily infer that the chemical phenomena taking place within the lead chamber in the manufacture of sulphuric acid were of the simplest kind; but upon further examination one soon reaches the conclusion that it is undoubtedly more complex. Many eminent chem. ists have spent years of research upon this process; its literature is enormous; and yet, the lead chamber process remains an unsettled question. In the last few years several chemists of the highest reputation have taken up anew the study of this process, and from two different points: First, the laws governing the reactions by which the manufacture may be brought to a successful working issue; and, secondly, the reactions themselres. It is, of course, almost ueedless for me to say that manufacturers are most interested in the first, and leave the latter field to those who cultirate pure science.

* Paper read at the regular monthly meeting of the Rhode Island Section of the American Chemical Society, Providence, R. I., February 18. 1892. 
As their results either confirm, modify, or disprove the conclusions formerly accepted, I trust that a brief resumé of the researches made and the theories proposed may not be entirely without interest at this time.

As an enumeration and analysis of all the papers bearing upon this subject that have appeared from time to time in the various technical journals wonld carry us beyond the scope of this paper, I intend this evening to take up only the theories of Hurter, Raschig, Lunge, Sorel, and Schertel.

Dr. F. Hurter, consulting chemist to the United Alkali Co., Limited, of England, has proposed in the Journal of the Society of Chemical Indust'y, vol. 1, pages 8, 49 and 83, a new and novel theory of the chemical reactions of the lead chamber, which he chooses to call "The Dynamic Theory."

Starting with the premise that the process in the lead chamber is completely stated in one of the following equations :

or

(1) $\mathrm{SO}_{2}+\mathrm{H}_{2} \mathrm{O}+\mathrm{O}+\mathrm{NO}_{2}=\mathrm{H}_{2} \mathrm{SO}_{4}+\mathrm{NO}_{2}$

(2) $\mathrm{SO}_{2}+\mathrm{H}_{2} \mathrm{O}+\mathrm{O}+\mathrm{N}_{2} \mathrm{O}_{3}=\mathrm{H}_{2} \mathrm{SO}_{4}+\mathrm{N}_{2} \mathrm{O}_{3}$

for the normal or primary reactions, $i$.e., those by which the greater amount of sulphuric acid is produced; and for the secondary reactions, $i$. e., those which are regarded as explaining the inevitable loss of nitrogen compounds, by either of the following equations :

(3) $2 \mathrm{SO}_{2}+2 \mathrm{H}_{2} \mathrm{O}+\mathrm{NO}_{2}=2 \mathrm{H}_{2} \mathrm{SO}_{4}+\mathrm{N}$

(4) $3 \mathrm{SO}_{2}+3 \mathrm{H}_{2} \mathrm{O}+2 \mathrm{NO}_{2}=3 \mathrm{H}_{2} \mathrm{SO}_{4}+\mathrm{N}_{2} \mathrm{O}$

or

(5) $2 \mathrm{SO}_{2}+2 \mathrm{H}_{2} \mathrm{O}+\mathrm{N}_{2} \mathrm{O}_{3}=2 \mathrm{H}_{2} \mathrm{SO}_{4}+\mathrm{N}_{2} \mathrm{O}$

(6) $3 \mathrm{SO}_{2}+3 \mathrm{H}_{2} \mathrm{O}+\mathrm{N}_{2} \mathrm{O}_{3}=3 \mathrm{H}_{2} \mathrm{SO}_{4}+\mathrm{N}_{2}$

Hurter attempts to show the connection thate xists between the dimensions of the chambers and the composition of the gases, the intensity of the reaction and the consequent temperature in the chambers as depending upon the method of combining single chambers into sets, by applying to the equation representing the primary reaction a new principle, which he borrows from the science of chemical dynamics. 
The particular principle which Hurter made use of in his investigation was the one referring to the velocity or rate of chemicith change, which may be stated as follows:

"The rate of chemical change depends upon, and is proportional to, the facility with which groups of molecules favorable to the particular change can form in the system in which the change occurs."

This principle is deduced from, and proved by, the dynamic theory of gases as advanced by Krönig, Clausius, and Clerk Maxwell.

Hurter's paper is largely of a mathematico-chemical nature. and being based on the differential and integral calculus, abounds in mathematical equations and expressions. These I will not weary you with by reproducing them here, but any one interested in the subject will find them stated, and, in general, explained in the papers cited.

The principal practical conclusions which he arrives at from his dynamic study of the process, based upon data derived from practice, are:

1. The work done by a given set of chambers depends principally on the nitrous products in action, and the strength of the acid condensed.

2. In a system composed of several chambers connected together, the energy of the action and the difference between the temperature insile and out of the chamber, decreases from one chamber to another in geometrical progression.

3. The temperature of the first chamber is a function of the relation between the capacity of this chamber and the total volume of the apparatus.

The two theories which are pushed to the front most at present by their respective adherents, are the theories of Raschig and of Lunge. Raschig, ${ }^{*}$ while conducting an in restigation in $188 \tilde{i}$, on the action of sulphites on nitrites, observed that sulphurnus acid

$"$ Ann. a. Chem. 241, 242-250. 
did not reduce nitrous acid, either in an acid or in an alkaline solution. Condensation products were always formed, which, by their splitting up into simple compounds, made it appear as if a reduction had taken place.

From the data thus obtained Raschig evolved a new theory of the formation of sulphuric acid, which, to say the least, is a novel and ingenious one.

According to this theory, the formation is due to a process of condensation in which dihydroxylaminesulphonic acid plays the principal rôle.

Raschig divides the process in to three stages:

(7) [a] $\mathrm{N}(\mathrm{OH})_{3}+\mathrm{H} . \mathrm{SO}_{2} \cdot \mathrm{OH}=(\mathrm{OH})_{2} \cdot \mathrm{N} \cdot \mathrm{SO}_{2} \cdot \mathrm{OH}+\mathrm{H}_{2} \mathrm{O}$,

That is, one molecule of normal nitrous acid $\left[\mathrm{N}(\mathrm{OH})_{3}\right.$, or $\mathrm{H} \mathrm{NO} \mathrm{N}_{2}+\mathrm{H}_{2} \mathrm{O}$ ] combines with one molecule of sulphurous acid $\left[\mathrm{SO}(\mathrm{OH})_{2}\right]$ to form dihydroxylaminesulphonic acid.

(8) [b] $(\mathrm{OH})_{2} \cdot \mathrm{N} \cdot \mathrm{SO}_{2} \cdot \mathrm{OH}+\mathrm{N}(\mathrm{OH})_{3}=\mathrm{H}_{2} \mathrm{SO}_{4}+2 \mathrm{NO}+2 \mathrm{H}_{2} \mathrm{O}$.

That is, decomposition of this intermediate product by nitrous acid in excess.

(9) [c] $2 \mathrm{NO}+\mathrm{O}+3 \mathrm{H}_{2} \mathrm{O}=2 \mathrm{~N}(\mathrm{OH})_{3}$

'That is, reoxidation of the nitric oxide formed into nitrous acid.

This theory would seem to explain why sulphurous anhydride does not react upon anhydrous nitrogen trioxide.

Finally, the author claims to find in this theory the explanation of the loss of nitrogen compounds which takes place in greater or less amount in the lead chambers. Thus, dihydroxylaminesulphonic acid can be decomposed by sulphuric acid and nitric oxide only when each molecule is in intimate contact, at the moment of decomposition, with one molecule of nitrous acid. If at this moment there is a deficiency of nitrous acid, the intermediate compound is split up into sulphuric acid and nitrous oxide $\left(\mathrm{N}_{2} \mathrm{O}\right)$; or, in pres- 
ence of sulphurous acid, it will give rise to hydroxylaminesulphonic acid, and finally to ammonia. 'Thus:

$$
\begin{gathered}
2(\mathrm{OH})_{2} \cdot \mathrm{N} \cdot \mathrm{SO}_{2} \cdot \mathrm{OH}=2 \mathrm{H}_{2} \mathrm{SO}_{4}+\mathrm{N}_{2} \mathrm{O}+\mathrm{H}_{2} \mathrm{O} . \\
(\mathrm{OH})_{2} \cdot \mathrm{N} \cdot \mathrm{SO}_{2} \cdot \mathrm{OH}+\mathrm{SO}_{2}+\mathrm{H}_{2} \mathrm{O}= \\
\text { H. OH. N. } \mathrm{SO}_{2} \cdot \mathrm{OH}+\mathrm{H}_{2} \mathrm{SO}_{4} \\
(\mathrm{OH})_{2} \cdot \mathrm{N} . \mathrm{SO}_{2} \cdot \mathrm{OH}+2 \mathrm{SO}_{2}+3 \mathrm{H}_{2} \mathrm{O}= \\
\mathrm{NH}_{3}+3 \mathrm{H}_{2} \mathrm{SO}_{4}
\end{gathered}
$$

To those who have not closely followed the recent adrances made in the sulphuric acid industry, it may be somewhat of a surprise to learn that Raschig actually found in erude chamber acid ammonia varying from 0.0025 to 0.0138 per cent.; and he even gous so far as to say that ammonia is always present in chamber acid, when it is not nitrous. Raschig's statement of the presence of ammonia in chamber acid has lecently been confirmed by Mr. R. Hasenclever, manager of the Rhenania Alkali Co., and by Dr. Haüsermann, of Griessheim, neal Frankfort, Germany.

This theory has been strongly opposed by Prof. Geo. Lunge, who claims that it does not take into account the existence of nitrosyl sulphate (the so-called chamber crystals), and that it does not harmonize with the facts of experience. Nitrous oxide, especially, which, according to the theory of Rischig, would be produced abundantly if the dihydroxylaminesulphonic acid did not meet a sufficient excess of nitrous acid, has never been found in any quantity in the gas of the lead chambers. And it is well, too, that such is the case, as otherwise there would be a great loss of nitrogen compounds, nitrous oxide being, as is well known, a very stable compound. Rischig fincts, as a strong support of his theory, the fact that ammonia has been found to exist in crude chamber acid, and considers this substance the final product of his reactions; but lunge thinks it is much more likely that the small quantities of ammonia found are formed more simply by the complete reduction of nitrogen compounds by the sulphur dioxide present. It applies then only to the secondary reactions.

According to Lunge, who has probavly, in recent years, given more time to and thrown more light on this subject than any other 
investigator, nitrosyl sulphate, or nitroso-sulphonic acid, techni cally known as chamber crystals, plays the principal part in the chemical mechanism of the formation of acid in the chambers. This compound, produced by the combination of sulphurous anhydride, water vapor, nitrogen trioxide, and oxygen, according to the following equation:

$$
2 \mathrm{SO}_{2}+\mathrm{N}_{2} \mathrm{O}_{3}+\mathrm{O}_{2}+\mathrm{H}_{2} \mathrm{O}=?\left(\mathrm{SO}_{2} \text {. OH. ONO }\right) \text {, }
$$

hovers as a mist in the atmosphere of the chamber and is immediately decomposed in the presence of an excess of steam, into. sulphuric acid, which falls to the bottom of the chamber, and nitrogen trioxide which is free to act upon a second molecule of sulphur dioxide, as follows:

(14) $2\left(\mathrm{SO}_{2}\right.$. OH. ONO) $+\mathrm{H}_{2} \mathrm{O}=2 \mathrm{SO}_{2}(\mathrm{OH})_{2}+\mathrm{N}_{2} \mathrm{O}_{3}$.

Nevertheless, in the front end of the first chamber, in presence of an excess of sulphurous vapors, the nitrosyl sulphate is denitrified, and the nitric oxide formed unites with the sulphur dioxide, steam, and oxygen, to again form the chamber crystals:

$$
\begin{aligned}
& 2 \mathrm{SO}_{2} \text {. OH. ONO }+\mathrm{SO}_{2}+2 \mathrm{H}_{2} \mathrm{O}=3 \mathrm{H}_{2} \mathrm{SO}_{4}+2 \mathrm{NO} \\
& 2 \mathrm{NO}+2 \mathrm{SO}_{2}+3 \mathrm{O}+\mathrm{H}_{2} \mathrm{O}=2\left(\mathrm{SO}_{2} . \mathrm{OH} . \mathrm{ONO}\right)
\end{aligned}
$$

The same compound can also be produced by the reaction of sulphurous anbydride upon nitric acid.

As to the direct conversion of sulphurous acid into sulphuric acid by the reduction of nitrogen tetroxide, or of nitrogen trioxide, according to the old theories, it is certain that it takes place only to a very insignificant amount.

Lunge and Naef, in a paper in the German Chemical Industry for 1884 , based upon a series of experiments carried out jointly by them, state that the composition of the nitrous gases in a chamber working under normal conditions is incompatible with the presence of nitrogen tetroxide. Up to within a short time, it was quite generally held that nitric oxide itself was produced only at the end of the process, by a secondary reaction; but recently nitric 
oxide has been found in the thick white fumes of the first working chamber behind the Glover tower, and has been explained in two ways: (a.) Sulphur dioxide, nitrogen compounds, oxygen, and water rapor meet here in the highest state of concentration, and here the highest temperature prevails: it is also here that the reactions proceed most actively, and the formation of sulphuric acid is most abundant. Under such conditions, it is not unlikely that a portion of the sulphur dioxide is directly oxidized to sulphuric acid, according to the equation:

or,

$$
\mathrm{SO}_{2}+\mathrm{NO}_{2}+\mathrm{H}_{42} \mathrm{O}=\mathrm{H}_{2} \mathrm{SO}_{4}+\mathrm{NO}
$$

$$
\mathrm{SO}_{2}+\mathrm{N}_{2} \mathrm{O}_{3}+\mathrm{H}_{2} \mathrm{O}=\mathrm{H}_{2} \mathrm{SO}_{4}+2 \mathrm{NO} \text {. }
$$

(b.) The nitrososulphonic acid already formed may here, owing to the excess of sulphur dioxide, stram, and the relatively high temperature prevailing, be denitrated, as follows:

$$
2 \mathrm{SO}_{2} . \mathrm{OH} . \mathrm{ONO}+\mathrm{SO}_{2}+2 \mathrm{H}_{2} \mathrm{O}=3 \mathrm{H}_{2} \mathrm{SO}_{4}+2 \mathrm{NO} \text {. }
$$

This reaction is the same as that taking place in the Glover tower immediately before, where the nitrous vitriol from the Gay Lussac tower, which is simply sulphuric acid holding in solution nitrososulphonic acid, is subjected to the same conditions.

Thus is the presence of nitric oxide in this part of the apparatus accounted for; and the nitric oxide so formed is undoubtedly afterwards oxidized, not simply by the axygen of the air, to form nitrogen tetroxide, as in the old theories of Berzelius, Dary, Weber and other's, which reaction has since been found to take place only in the presence of dry oxygen, which is quite different from the oxygen existing in the steam laden atmosphere of the lead chambers, but by oxygen in the presence of sulphur dioxide and steam to form nitrososulphonic acid; thus:

$$
2 \mathrm{SO}_{2}+2 \mathrm{NO}+3 \mathrm{O}+\mathrm{H}_{2} \mathrm{O}=2 \mathrm{SO}_{2} \text {. OH. ONO. }
$$

It may be well, perhaps, to mention here that the gases of the second chamber have been found to contain only nitrogen trioxide, and not nitric oxide, showing that the formation of nitric oxide observed in the gases of the first chamber was merely local. 
Lunge tersely sums up the results of his labors on this subject, which have appeared in full in the Berichte from time to time during the past fire or six years, in these words:

"The formation of sulphuric acid is determined, not by a succession of reductions and oxidations of nitrous gases, but by a condensation of nitrogen trioxide (or nitric oxide) with sulphurous acid and oxygen to nitrosyl sulphate, which is decomposed into sulphuric acid, with regeneration of nitrous acid (nitrogen trioxide)".

Theoretically, a small amount of certain nitrogen compounds, in the presence of an excess of oxygen, should be sufficient to oxidize an infinite amount of sulphurous acid to sulphuric acid. That this is not the case practically, acid manufacturers know only too well. This is the "bone of contention" of the technical chemist, at which many have gnawed; but only to find that their efforts have in a great measure been in vain. The cause of this variance between theory and practice may be attributed to two sources, namely, the mechanical loss of nitre and the chemical loss. The former is a very variable quantity, depending upon the construction, distribution and arrangement of the apparatus, is not the same in any two works, and need not concern us at this time. The chemical loss, which, in well constructed and properly managed works niakes up about seventy-five per cent. of the total loss, must most assuredly be taken into account by any one promulgating a new theory of the chamber process. Lunge recognizes this fact, and in his theory accounts for the loss in somewhat the following way. In normal working nitrogen trioxide is found only in the gaseous mixture at the exit from the last chamber. Under certain conditions the formation of nitrous oxide can take place by the action of sulphur dioxide upon nitrogen trioxide: but this reduction can occur only in presence of an excess of steam, or when the sulphuric acid in the chamber is weaker than it ought to be in normal working. The excess of steam in a chamber being usually only local, and generally only temporary, the reduction from this cause must occur very rarely. The formation of nitrogen tetroxide in the gas at the end of the system constitutes a much more important source of loss. It is formed by 
a condensation of nitric anhydride in the pan acid of the last chamber, but not in the nitrous aud of the condenser, for the coke packing, and, perhaps, also the traces of sulphurots acid which have escaped oxidation, reduce the nitrogen pentoxide. Innge makes the paradoxical statement that the production of nitrogen tetroxicie is entirely inderendent o: the amount of oxygen present in the gaseous mixture at the time, and that it takes place equally as well in lresence of a leficiency as of an excess of oxygen. It is caused solely by a rery large exees of nitrous products in the gases. In this case, the oxidation of the sulphurous acid is completed long before it gets to the last chamber, so that condensation of sulphuric acid is altogether wanting here. The nitrogen trioxide no longer encountering gaseous molecules with which to combine to form nitrososulplonic acid, is itself oxidized finally to the state of tetroxide in presence of a large excess of oxycen. A portion of this then combines with the chamber acid to form nitrosyl suphate and nitric anhydride: another portion escapes with the gases into the fay lussac alsorbing tower, where it is incompletely condensed, owing to the latter's inability to a the extra work thus put upon it, and uitimately excapes in to the atmosphere. thus becoming lost to the proeess.

E. Sorel, in a paper published in the bulletin de la soriete Lndustrielle de Hulhouse for April and May, 1889, formulates a theory a little different from that of Lange's.

While giring to nitrososulphonic acid an important part in the formation of sulphuric acid, he regards the chemical reactions as. a series of successive oxidations and reductions of the nitrogen compounds, caused by variations of concentration and of temperature of the sulphuric acid condensed. In presence of concentrated acid, nitrie oxide and sulphurons acid give rise to nitrosyl sulphate. An dilution of the suphuric acid this intermediate product is decomposed into sulphule acid and nitrogen trioxide. which oxidizes direetly the sulphurons acil. The principal and 
secondary reactions which take place according to Sorel's theory, may be represented by the following equations:

(22) $2 \mathrm{SO}_{2}+2 \mathrm{NO}+3 \mathrm{O}+\mathrm{H}_{2} \mathrm{O}=2 \mathrm{SO}_{2}$. OH. ONO,

(23) $2 \mathrm{NO}+\mathrm{O}=\mathrm{N}_{2} \mathrm{O}_{3}$,

(24) $2 \mathrm{NO}+\mathrm{O}_{2}=\mathrm{N}_{2} \mathrm{O}_{4}$,

(25) $2 \mathrm{SO}_{2}+\mathrm{N}_{2} \mathrm{O}_{3}+\mathrm{O}_{2}+\mathrm{H}_{2} \mathrm{O}=2 \mathrm{SO}_{2}$. OH. ONO,

(26) $2 \mathrm{SO}_{2}+2 \mathrm{~N}_{2} \mathrm{O}_{3}+\mathrm{O}+\mathrm{H}_{2} \mathrm{O}=2 \mathrm{SO}_{2}$. OH. $0 \mathrm{NO}+2 \mathrm{NO}$,

(27) $2 \mathrm{SO}_{2}+3 \mathrm{~N}_{2} \mathrm{O}_{3}+\mathrm{H}_{2} \mathrm{O}=2 \mathrm{SO}_{2}$. OH. $0 \mathrm{NO}+4 \mathrm{NO}$,

(28) $2 \mathrm{SO}_{2} . \mathrm{OH}$. ONO $+\mathrm{H}_{2} \mathrm{O}=2 \mathrm{SO}_{2}(\mathrm{OH})_{2}+\mathrm{N}_{2} \mathrm{O}_{3}$,

(29) $\mathrm{SO}_{2}+\mathrm{N}_{2} \mathrm{O}_{3}+\mathrm{H}_{2} \mathrm{O}=\mathrm{SO}_{2}(\mathrm{OH})_{2}+2 \mathrm{NO}$,

to which may be added the following reactions, which take place under certain conditions:

(30) $2 \mathrm{SO}_{2}+\mathrm{N}_{2} \mathrm{O}_{4}+2 \mathrm{H}_{2} \mathrm{O}=2 \mathrm{SO}_{2}(\mathrm{OH})_{2}+2 \mathrm{NO}$,

(31) $3 \mathrm{~N}_{2} \mathrm{O}_{4}+2 \mathrm{H}_{2} \mathrm{O}=4 \mathrm{HNO}_{3}+2 \mathrm{NO}$,

(32) $2 \mathrm{HNO}_{3}+\mathrm{SO}_{2}=\mathrm{SO}_{2}(\mathrm{OHI})_{2}+\mathrm{N}_{2} \mathrm{O}_{4}$.

From experiments recently performed by A. Schertel (Chemische Industrie, 1889, p. 80), on the manufacture of sulphuric acid, the observations upon which Lunge's theory rests have been confirmed in every particular.

Schertel showed experimentally the presence of nitrosyl sulphate in the atmosphere of a lead chamber working normally. The gases at the exit of the first chamber of a series were led through a lead pipe filled with coke, which, after having been carried down below the second chamber, made a turn into the leaden wall of the head of the second chamber. After allowing the gases to pass through this pipe for several weeks, nitrosyl sulplate (chamber crystals) was found upon opening the pipe. The crystals were distinctly formed, and were deposited upon the coke in the direction of the current of the gases, although the strength of the acid condensed in the pipe was kept much below that usually maintained in chambers.

I have now laid before you the source and extent of the latest information concerning the sulphuric acid process. From our present knowledge of the chemical reactions of the lead chamber, it would seem that of the many theories proposed, Lunge's har- 
monizes most closely with experience. And though exceptions may, and have, been taken to some of his conclusions, and althongh the existence of nitrogen trioxide in the gaseous state is not proven beyond a doubt, yet, I think I may say, without fear of contradiction, that Dr. Lunge has giren us the clearest and most trustworthy explanation of the formation of sulphuric wid that has vet appeared, and one that is not likely to be soon displaced.

\section{A REMARKABIA WA'TER FOR PUBLIC LSE.}

\section{BY A. A. BRENEMAN.}

I have had occasion recently to examine a sample of water taken from the public supply of Jong Island City. The water has been a source of much complaint. It is taken from driven wells at a point near Bowery Bay, on Long Island Sound, a few miles from New York City. The wells are sajd to be rather sballow.

The composition of the water was found to be as follows, in grains per C. S. gallon:

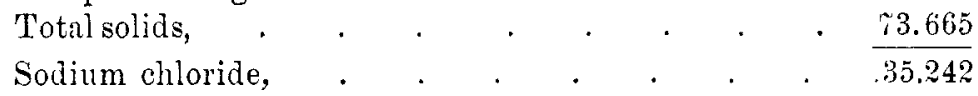

Calcium bicarbonate, . . . . . . . $\quad$. 6.840

Magnesium bicarbonate, . . . . . . . 10.536

Calcium sulphate, . . . . . . . . . 6.283

Magnesium sulphate, . . . . . . . .

Magnesium chloride, . . . . . . . . . . $\quad$. 7.584

Ferric oxire and alumina, . . . . . . . . . . 4.286

Organic and volatile water, . . . . . . . 4.505

Insoluble sediment, silica, etc., . . . . . . . $\quad .3 .892$

Less Water and $\mathrm{CO}_{2}$ of bicarbonates, $\quad \cdot \frac{6.930}{73.665}$

The water is probably a mixture of well water and sea water. The abundance of magnesium chloride, a characteristic ingredient of sea water, as well as the large excess of common salt, point to this conclusion. 